\title{
High resolution physical mapping of single gene fragments on pachytene chromosome 4 and 7 of Rosa
}

Ilya V. Kirov ${ }^{1,2,3}$, Katrijn Van Laere $3^{3^{*}}$ and Ludmila I. Khrustaleva ${ }^{1,2}$

\begin{abstract}
Background: Rosaceae is a family containing many economically important fruit and ornamental species. Although fluorescence in situ hybridization (FISH)-based physical mapping of plant genomes is a valuable tool for map-based cloning, comparative genomics and evolutionary studies, no studies using high resolution physical mapping have been performed in this family. Previously we proved that physical mapping of single-copy genes as small as $1.1 \mathrm{~kb}$ is possible on mitotic metaphase chromosomes of Rosa wichurana using Tyramide-FISH. In this study we aimed to further improve the physical map of Rosa wichurana by applying high resolution FISH to pachytene chromosomes.

Results: Using high resolution Tyramide-FISH and multicolor Tyramide-FISH, 7 genes (1.7-3 kb) were successfully mapped on pachytene chromosomes 4 and 7 of Rosa wichurana. Additionally, by using multicolor Tyramide-FISH three closely located genes were simultaneously visualized on chromosome 7. A detailed map of heterochromatine/euchromatine patterns of chromosome 4 and 7 was developed with indication of the physical position of these 7 genes. Comparison of the gene order between Rosa wichurana and Fragaria vesca revealed a poor collinearity for chromosome 7, but a perfect collinearity for chromosome 4.

Conclusions: High resolution physical mapping of short probes on pachytene chromosomes of Rosa wichurana was successfully performed for the first time. Application of Tyramide-FISH on pachytene chromosomes allowed the mapping resolution to be increased up to 20 times compared to mitotic metaphase chromosomes. High resolution Tyramide-FISH and multicolor Tyramide-FISH might become useful tools for further physical mapping of single-copy genes and for the integration of physical and genetic maps of Rosa wichurana and other members of the Rosaceae.
\end{abstract}

Keywords: Fluorescence In Situ Hybridization, Pachytene, Tyramide-FISH, Rosa, Physical map

\section{Background}

Rosa is a genus of the Rosaceae family consisting of approximately 90 genera and approximately 3000 species. Many of these are economically important such as Malus, Prunus, Pyrus, Fragaria, Rubus, Sorbus, Cotoneaster and Crataegus [1-5]. Approximately 150 species and more than 20.000 cultivars of Rosa are described [6]. Most species have a complex origin [7]. Interestingly, only 7 to 15 species have contributed to the original germplasm of the modern rose cultivars [8]. Rosa species have small genomes and a high level of heterozygosity. Basic chromosome number is $x=7$ [1], but

\footnotetext{
* Correspondence: Katrijn.Vanlaere@ilvo.vlaanderen.be

${ }^{3}$ Plant Sciences Unit, Applied Genetics and Breeding, Institute for Agricultural and Fisheries Research (ILVO), Caritasstraat 21, 9090 Melle, Belgium Full list of author information is available at the end of the article
}

ploidy levels range from diploid $(2 \mathrm{n}=2 \mathrm{x}=14)$ to decaploid $(2 \mathrm{n}=8 \mathrm{x}=56)$. Genomes of Pyrus [9], Prunus [10], Fragaria [4] and Malus [11] recently have been sequenced, providing valuable information for comparative genomics, gene cloning, marker development, QTL mapping and marker-assisted selection. Comparative analysis of these sequenced genomes has shed more light on the mode of evolution of some Rosaceae genera and species. In contrast, the organization of the Rosa genome has only been poorly investigated and the knowledge about the macro-synteny and collinearity of the Rose genome with other sequenced genomes Rosaceae family is poor.

Genetic maps have been widely used for comparative genomic and genome organization studies $[12,13]$. The distance between markers in genetic maps expressed in 
recombination frequencies, or centimorgans $(\mathrm{cM})$ is known to be unequally distributed along the chromosomes [14-17]. Gene order in genome regions with extremely low recombination frequency (e.g. centromeres, heterochromatin) cannot be revealed because of the low resolution of genetic mapping in these regions [18]. In addition, lack of collinearity between parental genomes used for development of the mapping population can cause inaccuracy in genetic maps [19]. In contrast to genetic maps, physical maps show real positions of DNA sequences on the chromosomes. Physical mapping using fluorescence in situ hybridization (FISH) does not depend on recombination frequency, therefore it can be used for gene mapping in "cold spot recombination" regions [18]. But FISH mapping has a lower efficiency than genetic mapping. The integration of physical and genetic maps provides a unique tool combining advantages of both types of maps. FISH-based physical maps have been developed and successfully integrated with genetic maps for many plant species (see review [20]). Direct visualization of DNA sequences on chromosomes by FISH is also a valuable for genome sequencing. FISH mapping improves the quality of genome assembly as demonstrated in tomato [21], cucumber [22] and Amborella [23].

Until now most of the cytogenetic studies in Rosa have been dedicated to karyotyping, chromosome number evaluation and rRNA (5S and 45S) gene mapping [24-28]. Further progress in FISH using individual genes or DNA clones (e.g. ESTs, BACs) is required for efficient cytogenetic map construction. Physical mapping of individual genes as small as $1.1 \mathrm{~kb}$ has proven to be possible on mitotic metaphase chromosomes of Rosa wichurana using TyramideFISH [29]. However, the resolution of Tyramide-FISH on the small mitotic Rosa chromosomes is very low which significantly hampers the construction of a physical map and the determination of the order of DNA sequences. The use of pachytene chromosomes would be an improvement for physical mapping [30]. Pachytene chromosomes are 7-40 times longer than mitotic metaphase chromosomes and therefore provide a higher resolution [21, 30]. Moreover, heterochromatic and euchromatic regions are distinguishable at the pachytene stage [31, 32]. Pachytene bivalents consist of 8 DNA strands instead of 4 in mitotic chromosomes, which also increases the sensitivity of FISH. Also important is that meiotic cells (pollen mother cells, or PMC) synchronously divide providing many cells in the same stage. High resolution FISH mapping on pachytene chromosomes has been used successfully in tomato [14, 21, 33-35] and Arabidopsis [31, 36-39]. However, for many plant species, pachytene preparation is still very challenging [30, 32, 40, 41].

Rosa wichurana is a diploid species $(2 \mathrm{n}=2 \mathrm{x}=14)$ that was involved in the origin of modern rose cultivars. This species is a valuable source for resistance to powdery mildew [42, 43] and has been used for construction of several genetic maps [42-46]. Moreover, R.wichurana is attractive object for molecular cytogenetic studies because it has intensively growing apical meristems and simple corolla, providing many anthers to be used for pollen mother cells (PMC) isolation and pachytene chromosome preparation. Therefore Rosa wichurana is a good model for the Rosa genus,

In this paper, we improved the SteamDrop protocol [47] for preparation of high quality pachytene chromosomes of Rosa wichurana. We performed physical mapping of 7 genes on pachytene chromosomes 4 and 7 of Rosa wichurana using a high resolution Tyramide-FISH and multicolour Tyramide-FISH. For the first time, multicolor Tyramide-FISH was applied to plant chromosomes. The protocol for multicolor-FISH allowed simultaneous visualization of the physical positions of three genes closely located on chromosome 7 of Rosa wichurana.

\section{Methods}

An orthology-based approach for probe design resulted in FISH probes with a length between $1.7 \mathrm{~kb}$ and $3 \mathrm{~kb}$

To isolate gene sequences on specific chromosomes of $R$. wichurana we used orthologous sequences of Fragaria vesca as a reference. The Rosa wichurana chromosomes 4 and 7 correspond to Fragaria vesca pseudochromosomes 7 (FvChr7) and 6 (FvChr6), respectively $[29,48]$. Several genes from Fragaria vesca pseudochromosomes 6 and 7 (FvChr 6 and FvChr 7) were randomly selected using the NCBI Map Viewer tool. These candidate genes were then used for BLASTN analysis against the genome of F. vesca (FraVesHawaii_1.0) in order to estimate their copy number in the Fragaria genome and to select only the single-copy genes. Seven genes [MLOlike proteins (MLO2 and MLO3), ATPase (AAA-2), Ubiquitin protein ligase (RIN-2), monodehydroascorbate reductase (MDAR), Villin-2-like, mannosylglycoprotein endo-beta-mannosidase (MGM)] which showed significant similarity only to the original sequences of Fragaria vesca were chosen for further analysis. The selected genes were used for BLASTN against nucleotide and EST databases of Rosa at NCBI. Full mRNA sequences of Rosa (Rosa multiflora) MLO genes (JX847132.1, JX847133) were used for primer design to isolate MLOlike genes from R.wichurana. Pairwise alignment of rose MLO mRNA sequences with orthologous Fragaria full length MLO sequences was performed to prevent primer annealing at the intron/exon border.

The other 5 Fragaria full-length gene sequences were used for BLASTN against transcriptome reads of $R$. x hybrid (NCBI accession number: SRX097578) or $R$. chinensis transcriptome reads or/and clusters 
(https://iant.toulouse.inra.fr/). In this way, rose reads with significant similarity to different parts of the Fragaria genes were found and used for primer design.

\section{Amplification and labeling of gene fragments}

Primers were designed using CLCbio Genomics Workbench version 7.0 to amplify gene fragments with a length more than $2 \mathrm{~kb}$ based on known Fragaria gene sequences and their location on the pseudochromosomes (Table 1). PCR products were generated using designed primers and genomic DNA of R.wichurana. PCR products were obtained with all 7 primer combinations. PCR with primers for villin resulted in a short PCR product of $900 \mathrm{bp}$, which is too short to be used in Tyramide-FISH experiments on Rosa. The other PCR products which ranged between $1.7 \mathrm{~kb}$ and $3 \mathrm{~kb}$ were cloned (Table 1) by pGEM-T easy (Promega, Madison, WI, USA) or by pPCR-TOPO kit (Invitrogen, Carlsbad, CA, USA). At least two clones were sequenced for each primer combination. The partial sequences of the clones used in this study are available as Additional file 1.

For physical mapping of PAL and P5CS genes, previously cloned gene fragments [29], were used.

Plasmid DNA was isolated by the PureLink Quick Plasmid Miniprep Kit (Invitrogen, CA, USA) and labeled by Biotin-Nick translation mix (Roche, Mannheim, Germany), Digoxigenin-Nick Translation mix (Roche) or by a "home-made" Biotin-Nick translation Mix using a "home-labeled" dUTP nucleotide. "Home labeled" nucleotides were prepared according to the previously described protocol [49] using aminoallyl-dUTP (Thermo Scientific) and Biotinamidohexanoic acid Nhydroxysuccinimide ester (Sigma-Aldish Co., LLC, France). Our "home-made" Nick translation mix (30 $\mu \mathrm{l})$ consists of 500 ng DNA, $83 \mu \mathrm{M}$ dATP, dGTP, dCTP, $10.6 \mu \mathrm{M}$ dTTP, $69 \mu \mathrm{M}$ biotin-dUTP, $300 \mu \mathrm{mU}$ rDNAse I (Ambion) and 5U DNA Polymerase I (Invitrogen) in NT buffer (50 mM Tris- $\mathrm{HCl}, \mathrm{pH} 7.8,5 \mathrm{mM} \mathrm{MgCl}_{2}$ ) containing $10 \mathrm{mM}$ beta-mercaptoethanol. The reaction

Table 1 Sequences of primers for gene fragment isolation and PCR results

\begin{tabular}{|c|c|c|c|c|c|}
\hline Gene & Abbreviation & Primers, 5'-3' & $\begin{array}{l}\text { Location on Fragaria } \\
\text { pseudo-chromosomes }\end{array}$ & $\begin{array}{l}\text { Expected length PCR } \\
\text { product (bp) }\end{array}$ & $\begin{array}{l}\text { Length obtained PCR } \\
\text { products (bp) }\end{array}$ \\
\hline \multirow[t]{2}{*}{ MLO-like protein } & \multirow[t]{2}{*}{ MLO3 } & $\begin{array}{l}\text { F: } \\
\text { AAAACACCAACATGGGCAGT }\end{array}$ & \multirow[t]{2}{*}{$\begin{array}{l}\text { FvChr 7: } \\
\text { 15397809..15393519 }\end{array}$} & \multirow[t]{2}{*}{1675} & \multirow[t]{2}{*}{1700} \\
\hline & & $\begin{array}{l}\text { R: } \\
\text { TTCCGAAAATCAAAGGTCGT }\end{array}$ & & & \\
\hline \multirow[t]{2}{*}{ MLO-like protein } & \multirow[t]{2}{*}{ MLO2 } & $\begin{array}{l}\text { F: } \\
\text { AGGATTTCAAGGTCGTGGTG }\end{array}$ & \multirow[t]{2}{*}{$\begin{array}{l}\text { FvChr6: } \\
\text { 34503533..34507423 }\end{array}$} & \multirow[t]{2}{*}{1852} & \multirow[t]{2}{*}{1800} \\
\hline & & $\begin{array}{l}\text { R: } \\
\text { TGGTCGGCTAGCATTITTCT }\end{array}$ & & & \\
\hline \multirow[t]{2}{*}{ ATPase } & \multirow[t]{2}{*}{ AAA-2 } & F: GTTCCCTTTGTCATTGCAG & \multirow{2}{*}{$\begin{array}{l}\text { FvChr7: } 21485846 . . \\
21481090\end{array}$} & \multirow[t]{2}{*}{2718} & \multirow[t]{2}{*}{3400} \\
\hline & & R: ACGGCCTCTTCATCAATT & & & \\
\hline \multirow[t]{2}{*}{ Ubiquitin protein ligase } & \multirow[t]{2}{*}{ RIN-2 } & $\begin{array}{l}\text { F: } \\
\text { TCCTTCAGCTACACCATTGAC }\end{array}$ & \multirow[t]{2}{*}{$\begin{array}{l}\text { FvChr7: } \\
\text { 19866961..19871497 }\end{array}$} & \multirow[t]{2}{*}{2228} & \multirow[t]{2}{*}{2500} \\
\hline & & R: AAATTGCGCGTTCCTACT & & & \\
\hline \multirow{2}{*}{$\begin{array}{l}\text { Monodehydroascorbate } \\
\text { reductase }\end{array}$} & \multirow[t]{2}{*}{ MDAR } & F: GAGGCGGTATGGTTAATTT & \multirow{2}{*}{$\begin{array}{l}\text { FvChr6: } \\
\text { 12864594..12867898 }\end{array}$} & \multirow[t]{2}{*}{2417} & \multirow[t]{2}{*}{2800} \\
\hline & & R: AAACTTGGGCTTTGGTGA & & & \\
\hline \multirow[t]{2}{*}{ Villin-2-like } & \multirow[t]{2}{*}{ Villin } & $\begin{array}{l}\text { F: } \\
\text { CTCGCTTCTTCACAACATACT }\end{array}$ & \multirow[t]{2}{*}{$\begin{array}{l}\text { FvChr6: } \\
\text { 33309900..33321407 }\end{array}$} & \multirow[t]{2}{*}{3851} & \multirow[t]{2}{*}{900} \\
\hline & & R:TTCACTGCCATTTTCATCCT & & & \\
\hline \multirow[t]{2}{*}{$\begin{array}{l}\text { Mannosylglycoprotein endo- } \\
\text { beta-mannosidase }\end{array}$} & \multirow[t]{2}{*}{ MGM } & $\begin{array}{l}\text { F: } \\
\text { CGGCATGGAAAATGAGTCAA }\end{array}$ & \multirow[t]{2}{*}{ FvChr6: $5180627 . .5186123$} & \multirow[t]{2}{*}{3017} & \multirow[t]{2}{*}{3000} \\
\hline & & R: GAACAAAGGGATCTGCCA & & & \\
\hline \multirow[t]{2}{*}{$\begin{array}{l}\text { Phenylalanine ammonia } \\
\text { lyase } \mathrm{e}^{\mathrm{a}}\end{array}$} & \multirow[t]{2}{*}{ PAL } & $\begin{array}{l}\text { F: } \\
\text { ACCACTGGKTTTGGTGCWAC }\end{array}$ & $\begin{array}{l}\text { FvChr6:34874086- } \\
34877587\end{array}$ & - & 1700 \\
\hline & & $\begin{array}{l}\text { R: } \\
\text { CCYTTGAASCCATAATCCAA }\end{array}$ & & & \\
\hline $\begin{array}{l}\text { Pyrroline-5-Carboxylate } \\
\text { Synthase }\end{array}$ & P5CS & $\begin{array}{l}\text { F: } \\
\text { GCTGGCATCCCTGTTGTTAT }\end{array}$ & $\begin{array}{l}\text { FvChr7: } 17624431- \\
17630820\end{array}$ & - & 1700 \\
\hline & & $\begin{array}{l}\text { R: } \\
\text { CTTCGGATCGCTAATGAAGC }\end{array}$ & & & \\
\hline
\end{tabular}


was done at $15{ }^{\circ} \mathrm{C}$ for $2 \mathrm{~h}$ and stopped by heating at $80{ }^{\circ} \mathrm{C}$ for $5 \mathrm{~min}$.

Clone pTa71 containing a 9-kb EcoRI fragment of the 45S rDNA from wheat [50], was labeled using the Digoxigenin-Nick Translation Mix (Roche).

\section{Pachytene chromosome preparation}

Rosa wichurana plants were grown in a glass greenhouse under natural conditions in the temperate climate of East Flanders, Belgium. Five to ten anthers from each flower bud were placed on the slide and a drop of $60 \%$ acetic acid was added. Anthers were then disrupted by a needle, heated at $55{ }^{\circ} \mathrm{C}$ for $1 \mathrm{~min}$ and squashed with a coverslip. The meiotic stages were observed under phase contrast (Zeiss AxioImager M2, Zeiss Company, Germany). Flower buds with most of the anthers containing PMCs in pachytene stage were fixed in Carnoy's solution (3:1, ethanol:acetic acid) for at least $3 \mathrm{~h}$ and transferred into $70 \%$ ethanol for storage at $-20{ }^{\circ} \mathrm{C}$.

Flower buds were washed in water for 30-40 $\mathrm{min}$ and transferred into $10 \mathrm{mM}$ citric buffer (citric acid, sodium citrate dehydrate, $\mathrm{pH}$ 4.7-4.8) for 15-30 min. Anthers were then separated using a pincet and transferred into $50 \mu \mathrm{l}$ enzyme mixture. One-third to one-fourth of all anthers from a single flower bud were used for the preparation of one tube of cell suspension. The enzyme mixture contained $0.6 \%$ Pectolyase Y-23 (Kikkoman, Tokyo, Japan), 0.6 \% Cellulase Onozuka R-10 (Yakult Co. Ltd., Tokyo, Japan) and $0.2 \%$ Cytohelicase (SigmaAldish Co. LLC, France). A modified SteamDrop protocol [47] was used for cell suspension and chromosome preparation. Briefly, $10 \mu \mathrm{l}$ of cell suspension were added on the slide; after $8-10 \mathrm{~s}$, a drop of $22-28 \mu \mathrm{l}$ of $1: 1$ ethanol:acetic acid was applied. When the slide surface became granule-like (50-80 s) steam (3-5 s) was applied to the slides and a second drop of 15-18 $\mu \mathrm{l}$ of 1:2 ethanol:acetic was added. When the granule-like surface appeared again on the slide, steam was applied and $300 \mu \mathrm{l}$ of $45 \%$ or $60 \%$ acetic acid was added. Then slides were incubated on a heating plate $\left(42{ }^{\circ} \mathrm{C}\right)$ for $15-30 \mathrm{~s}$. A needle was used to spread the drop of acetic acid over the ring of cells on the slide. Acetic acid was removed by positioning the slide vertically on filter paper.

\section{Tyramide-FISH}

We used the Tyramide-FISH protocol with an indirect detection system previously optimized for $R$. wichurana mitotic chromosomes [29]. Prehybridization procedures for single color and two color Tyramide-FISH included overnight incubation at $37{ }^{\circ} \mathrm{C}, 4 \%$ paraformaldehyde treatment $(6-7 \mathrm{~min})$ and dehydration in an ethanol series $(70 \%, 90 \%$ and $100 \%)$. Probe hybridization and detection for single color Tyramide-FISH were carried out as described [29]. For two color Tyramide-FISH probe hybridization was conducted according to Kirov et al. [29] with a hybridization mixture containing two labeled probes: digoxigenin labeled MLO2 gene and biotin labeled PAL gene. The two probes were detected sequentially. First, the PAL gene was detected by Streptavidin-HRP (1:100, PerkinElmer, Belgium) followed by application of tyramide-biotin (1:25 in plus amplification buffer (PerkinElmer)) application. Then HRP (Horse Radish Peroxidase) was inactivated using $3 \%$ hydrogen peroxide $(20 \mathrm{~min})$. After this slides were simultaneously incubated with streptavidin-Cy3 (1:100, Sigma-Aldrich)) and anti-digoxigenin-HRP (1:100, Roche) diluted in blocking buffer (Roche) followed by tyramide-biotin amplification. Biotin from the second layer was detected by Streptavidin-FITC (Vector Laboratories, Burlingame, CA).

Zeiss AxioImager M2 (400x and 1000× magnification) equipped with an AxioCam MRm camera and Zen software (Zeiss, Zaventem, Belgium) were used to analyse the hybridisation signal and to capture all images. Relative distance to the signal was calculated by the following formula:

Distance from telomere of the long arm to the signal $x$ $100 \%$ / length of whole arm.

Images were analyzed using ImageJ software. Signal position was measured using the Micromeasure software [51], version 3.3 (http://sites.biology.colostate.edu/MicroMeasure/). Pachytene chromosomes with a similar length were chosen for calculation of centromere index and percentage of heterochromatin. At least 9 pachytene chromosomes were used to determine the location of the Tyramide-FISH signals (Table 2).

\section{Results}

High quality pachytene chromosome preparations suitable for Tyramide-FISH were obtained for Rosa wichurana

Flower buds with a hypanthium size of 3-5 mm had the most PMCs in pachytene stage although also PMC in metaphase I and tetrad stages could be observed in the same flower bud (Fig. 1).

DAPI staining of $R$ wichurana pachytene chromosomes did not reveal strong heterochromatin blocks that can be used as cytogenetic markers. All centromeres are the weakest stained parts of the chromosomes flanked by pericentromeric heterochromatin. Only chromosomes 4 and 7 are distinguishable by their clear presence of heterochromatin patterns on the short arms (Fig. 2, Table 2). In addition chromosome 7 possesses NOR (nucleolar organizing regions) on the short arm.

To prepare pachytene chromosomes, the SteamDrop protocol was modified by adding a drop of $60 \%$ acetic acid after the second steam application and before drying the cells. This modification improved the chromosome spreading and resulted in a clear $45 \mathrm{~S}$ 
Table 2 Characteristics of pachytene chromosome 4 and 7 of R. wichurana

\begin{tabular}{|c|c|c|c|c|c|c|c|c|c|}
\hline $\begin{array}{l}\text { Chr. } \\
\text { Nr. }\end{array}$ & $\begin{array}{l}\text { Chromosome } \\
\text { length }(\mu \mathrm{m})\end{array}$ & $\begin{array}{l}\text { Short arm } \\
(\mu \mathrm{m})\end{array}$ & $\begin{array}{l}\text { Long arm } \\
(\mu \mathrm{m})\end{array}$ & $\begin{array}{l}\text { Short arm } \\
\text { heterochromatin (\%) }\end{array}$ & 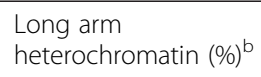 & $\begin{array}{l}\text { Total } \\
\text { heterochromatin }(\%)^{c}\end{array}$ & $\begin{array}{l}\text { Centromere } \\
\text { index }\end{array}$ & NOR & $\mathrm{n}^{\mathrm{d}}$ \\
\hline 4 & $45.6 \pm 5.4$ & $11.4 \pm 1.4$ & $34.0 \pm 4.0$ & $62.0 \pm 6.0$ & $21.0 \pm 4.5$ & $31.0 \pm 4.0$ & $25.0 \pm 0.5$ & & 7 \\
\hline 7 & $38.4 \pm 4.2$ & $4.0 \pm 0.6$ & $33.3 \pm 3.5$ & $88.0 \pm 6.7$ & $16.8 \pm 4.4$ & $24.3 \pm 2.3$ & $10.3 \pm 0.8$ & + & 9 \\
\hline
\end{tabular}

a calculated by the formula: length of heterochromatin of the short arm $\times 100 \%$ /total length of the short arm

b - calculated by the formula: length of heterochromatin of the long arm $\times 100 \% /$ total length of the long arm

c - calculated by the formula: (length of heterochromatin of the short arm + length of heterochromatin of the long arm) $\times 100 \% /$ total length of the chromosome

d- Number of pachytenes used in the measurements of chromosome lengths and calculation of \% heterochromatin

rDNA signal on chromosome 7 of Rosa wichurana (Fig. 3a). Moreover, application of Tyramide-FISH on pachytene chromosomes revealed differences in signal frequency between the slides prepared by 15, 30 and $60 \mathrm{~s}$ of acetic acid treatment on the heating plate (the final step in modified SteamDrop procedure). The maximum signal-to-noise ratio (visual observation) and signal frequency $(60-70 \%)$ were obtained on the slides prepared by $30 \mathrm{~s}$ of acetic acid treatment. Both $15 \mathrm{~s}$ and $60 \mathrm{~s}$ of acetic acid treatment resulted in low signal frequency (10-15\%). In addition the level of background was higher for $15 \mathrm{~s}$ and very low for $60 \mathrm{~s}$.

\section{Pachytene chromosomes of Rosa wichurana provide up to 20 times higher resolution compared to mitotic chromosomes}

The total pachytene chromosome length varied between $235 \mu \mathrm{m}$ and $411 \mu \mathrm{m}$, which is $10-20$ times longer than the mitotic chromosomes $(20 \mu \mathrm{m} \pm 1 \mu \mathrm{m}$; [29]). The chromatin compactization of pachytene chromosomes of

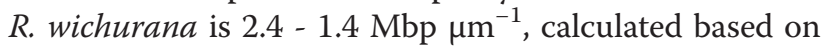
the genome size of $562 \mathrm{Mbp}$ [52]. Taken into account the $0.2 \mu \mathrm{m}$ - resolution limit for fluorescence microscopy, it can be concluded that the spatial resolution of FISH on $R$. wichurana pachytene chromosomes is between 300-500 kb.

\section{High resolution physical mapping of gene fragments using Tyramide-FISH}

Seven gene fragments resulted in clear Tyramide-FISH twin signals on one pachytene bivalent (Fig. 3, Table 3). Only Tyramide-FISH for the gene RIN-2 resulted in multiple signals distributed over all the chromosomes.
Three genes were mapped on the long arm of pachytene chromosome 4 . The AAA-2 gene was mapped in the distal part (relative distance of $8.0 \pm 1.0 \%$ ) of chromosome 4 (Fig. 3c). The MLO3 and P5CS genes were mapped on more proximal positions, with a relative distance of $44.0 \pm 1.5 \%$ and $30.0 \pm 2.0 \%$, respectively (Fig. 3b).

Four genes (MLO2, MDAR, MGM and PAL) were mapped on chromosome 7. MGM was located in the distal part of the chromosome (relative distance of $18.0 \pm$ $1.5 \%$ ) (Fig. 3d). PAL, MDAR (Fig. 3e) and MLO2 genes were physically mapped in the middle of the long arm of the the pachytene chromosome 7 with relative positions of $46.6 \pm 1.0 \%, 52.0 \pm 1.5 \%$ and $44.8 \pm 0.5 \%$, respectively. Tyramide-FISH with pairs of the genes (MGM + MLO2, MLO2 + PAL and PAL + MDAR) confirmed the order and location of all genes on the same chromosome.

\section{Tightly linked genes can be distinguished using high resolution multicolor Tyramide-FISH}

Because PAL and MLO2 are very closely located on chromosome 7, Tyramide-FISH with PAL and MLO2 resulted in one large signal. Therefore, to determine the order of PAL and MLO2 genes on chromosome 7, multicolor Tyramide-FISH was applied (Fig. 3f). Twocolor Tyramide-FISH revealed the order of MLO2, PAL and MGM genes on the same chromosome. In $58 \%$ of the observed pachytene cells $(n=17)$ closely located red (PAL) and green (MLO2) signals were observed, while the red and green signals in the other $42 \%$ of pachytene cells partially overlapped. These results suggest that the distance between MLO2 and PAL genes is on the border of the spatial resolution of Tyramide-FISH on pachytene

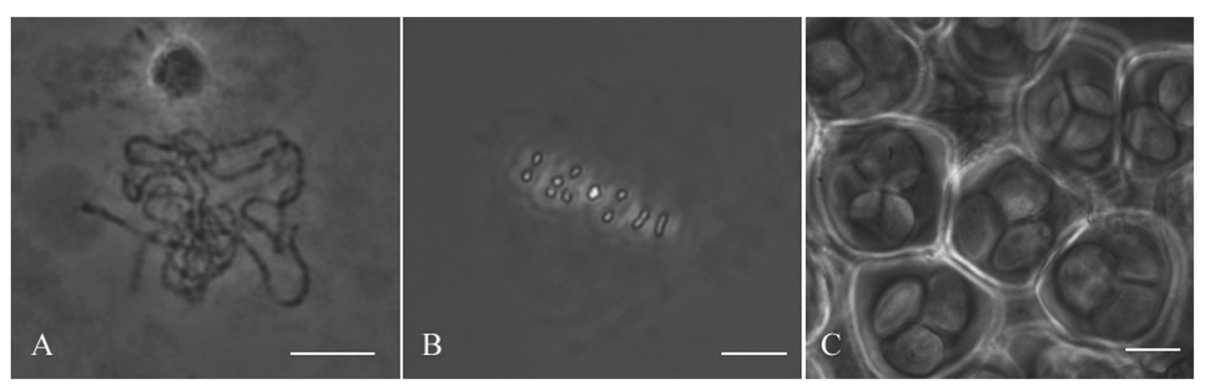

Fig. 1 Pachytene (a), Metaphase I (b) and Tetrad (c) stages found in a R. wichurana flower bud. Bars = $10 \mu \mathrm{m}$ 

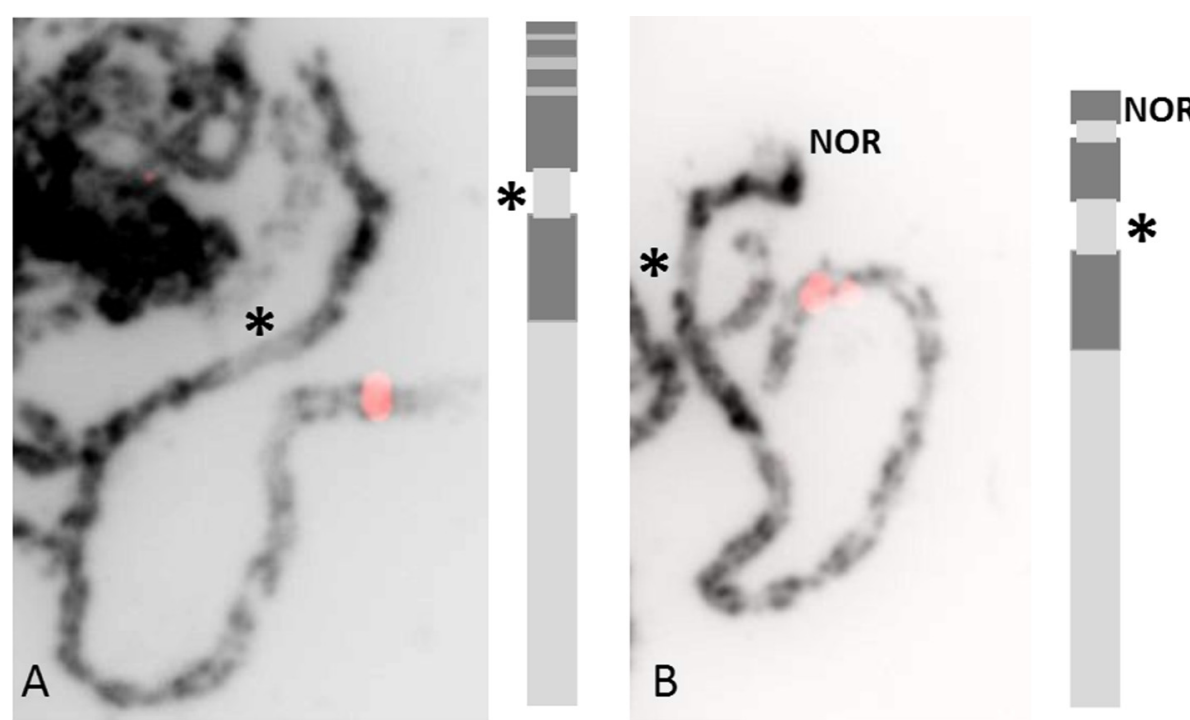

Fig. 2 Inverted DAPI pictures and ideogram of chromosome 4 (a) and 7 (b). Red signals showed the location of AAA-2 (a) and MGM (b) genes after Tyramide-FISH to verify the correct chromosome number. Stars indicate the centromere position on the chromosomes
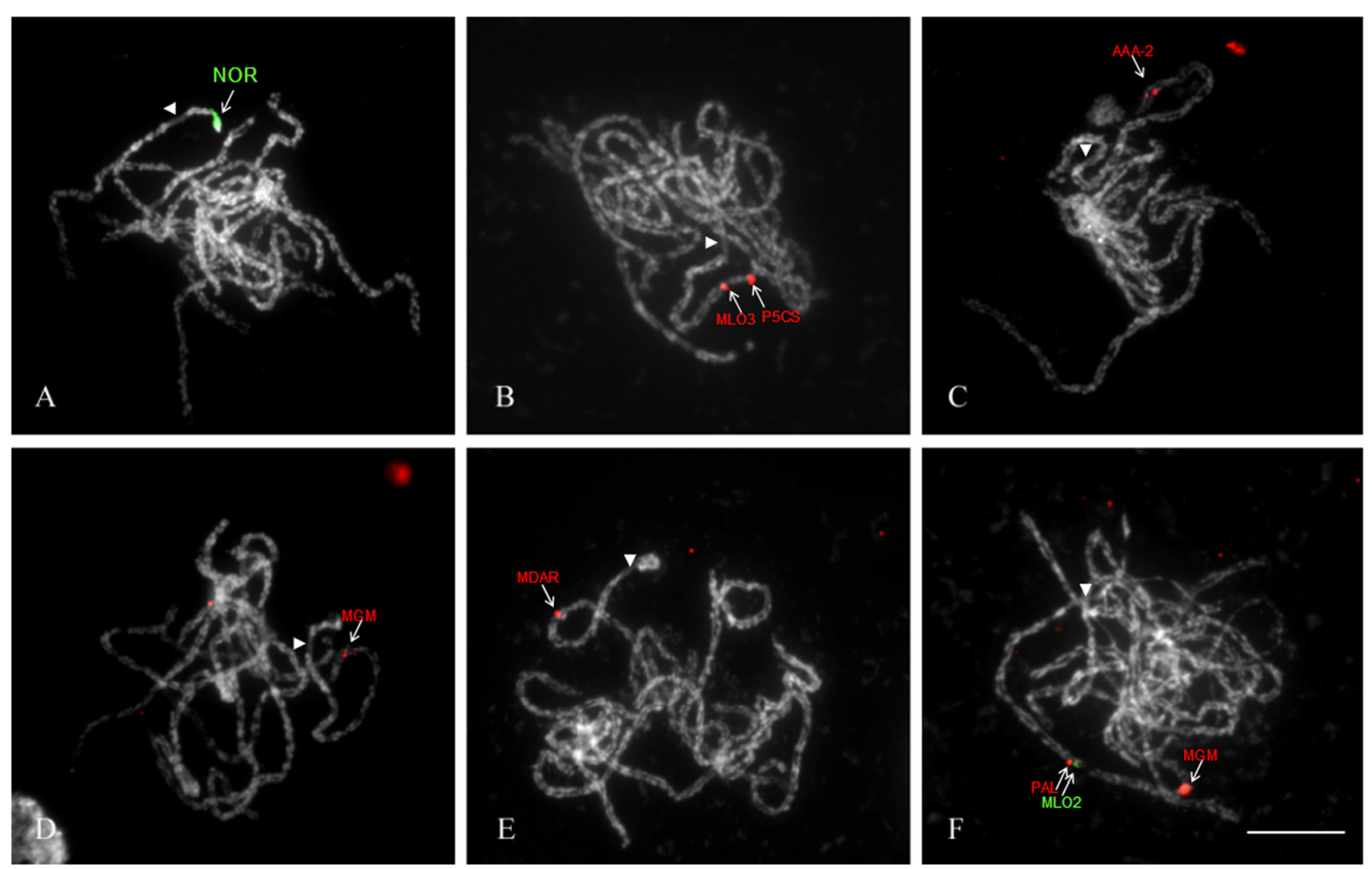

Fig. 3 In situ physical mapping of genes on pachytene chromosomes of Rosa wichurana. FISH with Dig-labeled 455 rDNA (pTA71 plasmid) (a); Tyramide-FISH with MLO3 and P5CS genes, both labeled with biotin (b) and with AAA-2 gene, labeled with biotin (c); Tyramide-FISH with MGM gene labeled with biotin (d) and MDAR gene labeled with biotin (e); Sequential multicolor Tyramide-FISH with digoxigenin labeled MLO2 gene and biotin labeled PAL and MGM genes (f). Centromere of the chromosome that contains the physically mapped gene(s) is indicated by an arrowhead. Bar $=10 \mu \mathrm{m}$ 
Table 3 Physical location of the target genes on R. wichurana pachytene chromosomes

\begin{tabular}{lcc}
\hline Gene name & Chromosome number/ arm & $\begin{array}{c}\text { Location on chromosome } \\
\left.\operatorname{arm}^{(\%)}\right)^{\mathrm{a}}\end{array}$ \\
\hline MLO3 & $4 / \mathrm{L}$ & $44.0 \pm 1.5$ \\
AAA-2 & $4 / \mathrm{L}$ & $8.0 \pm 1.0$ \\
P5CS & $4 / \mathrm{L}$ & $30.0 \pm 2.0$ \\
MLO2 & $7 / \mathrm{L}$ & $44.8 \pm 0.5$ \\
MDAR & $7 / \mathrm{L}$ & $52.0 \pm 1.5$ \\
MGM & $7 / \mathrm{L}$ & $18.0 \pm 1.5$ \\
PAL & $7 / \mathrm{L}$ & $46.6 \pm 1.0$ \\
RIN-2 & Multiple signals & - \\
\hline
\end{tabular}

a- Distance from telomere of the long arm to the signal $\times 100 \%$ / length of whole arm

chromosome of $R$. wichurana. Based on the length of the pachytene bivalents carrying non-overlapped signals $(41 \pm 1.5 \mu \mathrm{m})$, the relative length of the mitotic chromosome 7 (10.0 $\pm 0.1 \%$; Kirov et al. [47]), the genome size for $R$. wichurana (562 $\mathrm{Mb} / 1 \mathrm{C}$, [52]) and $0.2 \mu \mathrm{m}$ - resolution limit for light microscope, we may calculate the physical distance between the MLO2 and PAL genes which is about $270 \mathrm{~kb}$. An overview of the genes located on chromosome 4 and chromosome 7 and their order is shown in Fig. 4.

\section{Discussion \\ Chromosome preparation is a key factor for Tyramide- FISH success}

To our knowledge, this is the first report on the application of FISH on pachytene chromosomes of a member of Rosaceae family. Pachytene chromosome preparation using the SteamDrop procedure has number of advantages [47]: 1) After cell suspensions are prepared they can be stored for months; 2) The chromosome preparation takes only $3-5$ min from made cell suspensions; and 3) up to 20 slides can be prepared from one flower bud. Here we modified the SteamDrop protocol [47] for easy pachytene chromosome preparation of Rosa wichurana. One of the modifications is a final treatment of cells by acetic acid providing better chromosome spreading and

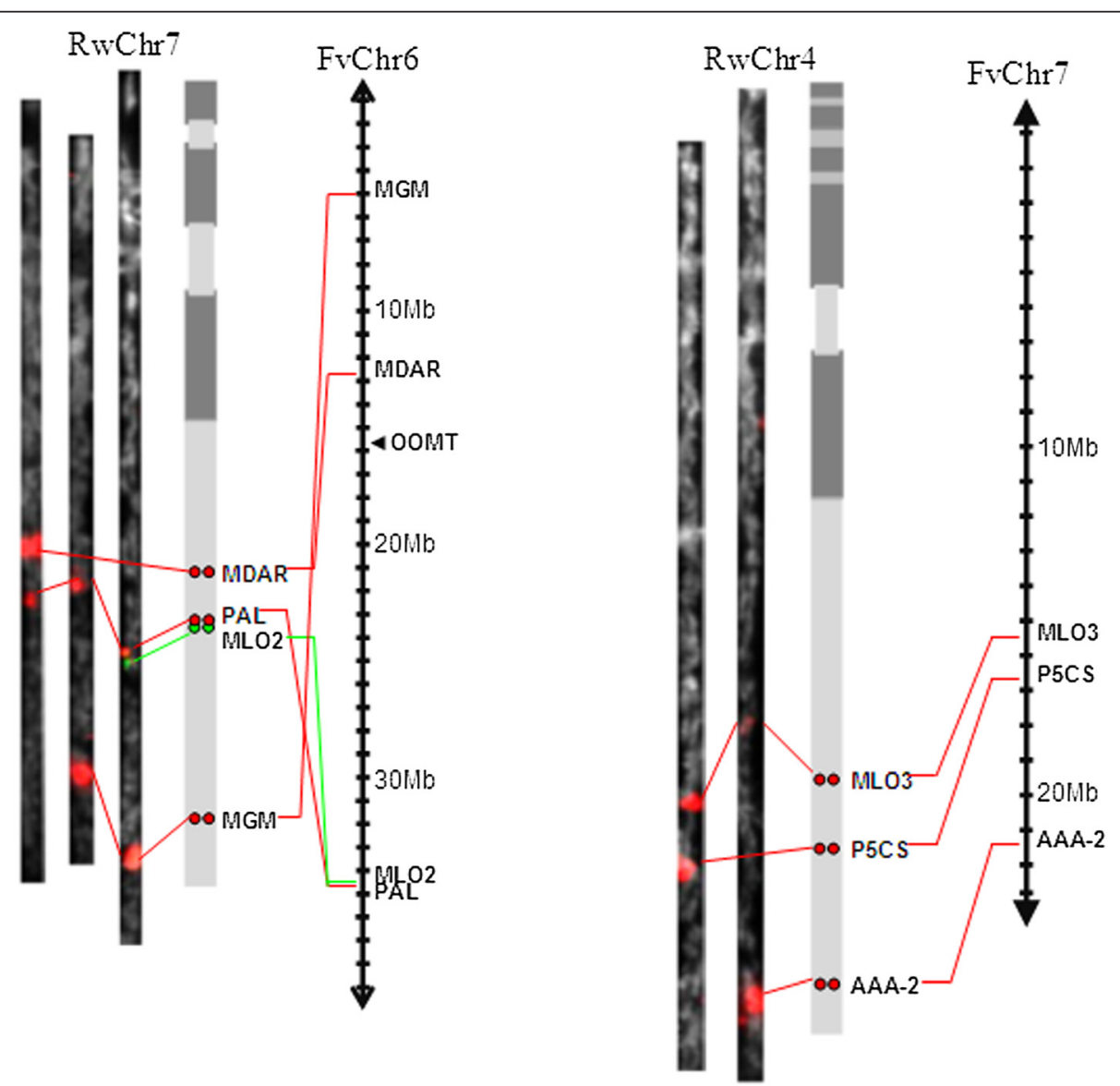

Fig. 4 Physical location of 7 target genes on R. wichurana chromosome 7 (RwChr7, left) and 4 (RwChr4, right) versus Fragaria vesca pseudochromosomes 6 (FvChr6) and 7 (FvChr6), correspondently. Signals are shown on digitally straightened pachytene chromosomes and on an ideogram of $R$. wichurana and compared with pseudochromosome 6 (FvChr6) and 7 (FvChr7) of the F. vesca genome sequence 
Tyramide-FISH results. The time of treatment with acetic acid significantly influences the Tyramide-FISH results. Over-treatment as well as insufficient treatment resulted in a manifold reduction of signal frequency. PMCs require an optimal time of acetic acid treatment for reducing the amount of cytoplasm and the thickness of the organic layer covering the chromosomes [53]. Overtreatment of chromosomes by acetic acid results in histone elimination [54] and chromosome becomes flatten which reduces the chromatin accessibility [55] and the amount of electron-rich amino acids (e.g., tyrosine, tryptophan, phenylalanine) required for tyramide anchoring after HRP activation [56]. Therefore the chromosome preparation procedure is the most important step in high resolution physical mapping using Tyramide-FISH and should be optimized first to obtain satisfactory results.

\section{Resolution of FISH on pachytene chromosomes of R. wichurana}

Mitotic chromosomes of Rosa wichurana are very small, ranging from 2.2 to $3.7 \mu \mathrm{m}$ in length [29]. Their small size leads to a lower resolution (5-5.5 Mb) when using FISH, which hampers the use of FISH for physical mapping in $R$. wichurana. In contrast, pachytene chromosomes of $R$. wichurana are up to 20 times longer than mitotic chromosomes, which is comparable with data obtained on banana [41], Arabidopsis [39], tomato [57], Medicago truncatula [32] and rice [58]. Based on the genome size for $R$. wichurana (562 Mb/1C, [52]), $0.2 \mu \mathrm{m}$ - resolution limit for light microscope and total length of pachytene chromosomes $(235-411 \mu \mathrm{m})$ we can conclude that the spatial resolution of FISH mapping on $R$. wichurana pachytene chromosomes is $270-500 \mathrm{~kb}$. Pachytene stage and location of probe in euchromatin or heterochromatin region influence on FISH resolution [14]. Resolution of FISH is much higher for zygotene, leptotene and early pachytene. For example the order of partially overlapped BAC clones can be determined on early pachytene chromosomes [35]. DNA condensation varies significantly along a pachytene chromosome - it is highly condensed in heterochromatin regions and less condensed in euchromatin regions $[30,59]$. For example, the FISH resolution in the euchromatic regions of tomato pachytene is 10 times higher than in heterochromatin regions [30]. For Rosa wichurana, clear pericentromeric heterochromatin was observed on all pachytene chromosomes but also a number of weak stained heterochromatin bands were identified in euchromatic parts. Therefore, further study is necessary in order to estimate the precise resolution of FISH in heterochromatin and euchromatin of pachytene chromosomes of $R$. wichurana to convert microscopic distance into base pairs.

\section{Advantages and limitations of Tyramide-FISH for high- resolution physical mapping}

Tyramide-FISH on pachytene chromosomes resulted in a higher signal frequency compared to mitotic chromosomes. We were able to visualize the signals on $70 \%$ of the pachytene spreads. This is much higher than reported for Tyramide-FISH on mitotic chromosomes $[29,60]$. Moreover, Tyramide-FISH allows physical mapping of short DNA fragments. Gene fragments with a length as small as $1.7 \mathrm{~Kb}$ were successfully visualized on pachytene chromosomes of $R$. wichurana. Because most of the genes are free of repetitive DNA it is not necessary to use blocking DNA (e.g. $C_{o} t$ fraction) for physical mapping as is the case for physical mapping by BAC-FISH [61]. The efficiency of physical mapping using Tyramide-FISH is high. In this study 7 out of the $8(87.5 \%)$ isolated genes were successfully mapped on the pachytene chromosomes.

However, Tyramide-FISH have some disadvantages for physical mapping. Tyramide-FISH is highly dependent on the quality of the slide preparation. And another drawback of Tyramide-FISH is that sometimes gene fragments give multiple signals which cannot be reliably physically mapped, e.g., the RIN-2 probe in this study and [62]. In addition, multicolor Tyramide-FISH is a quite time-consuming process because each probe is detected sequentially.

\section{Advantages of an orthology-based probe design}

Different strategies can be used for single gene probe design for FISH mapping. One approach is the use of EST [29] or genomic sequences $[59,62]$ of genes for primer design and further cloning of PCR products. Another strategy is to isolate orthologous gene fragments of one genus based on the whole genome sequence of another closely related genus. This approach is useful for the isolation of genes of which no full-length sequences or mRNA sequences are available in databases. This latter approach allowed for Rosa wichurana the design of specific primers and amplification of gene fragments with the predicted size based on the genome of Fragaria vesca. Moreover, it allowed the development of probes containing exon-intron fragments of the genes. On the contrary, EST clones often are too short as FISH probes and can contain highly conserved exon sequences which cross hybridize with other members of the same gene family, resulting in multiple signals ditributed along all chromosomes [62].

Macro-synteny between R. wichurana chromosome 4 and 7 and Fragaria vesca pseudochromosomes

In our study, three genes, physically mapped on $R$. wichurana chromosome 4 (RwChr4), showed a perfect collinearity with $F$. vesca pseudochromosome 7 (FvChr7). 
The collinearity between $R$. wichurana chromosome 7 and FvChr6, however, is not well established yet. Tyramide-FISH results on mitotic chromosomes showed that OOMT and PAL genes, belonging to the same pseudochromosome FvChr6 of F.vesca, were located on two different chromosomes (chromosome 1 and 7) in $R$. wichurana [29]. Previously Gar et al. [48] also found that genes located on FvChr6 are located on two different linkage groups of $R$. wichurana, suggesting an ancient translocation event. Here we physically mapped 3 additional genes located terminal (MLO2 and MGM) and proximal (MDAR) on FvChr6. Our Tyramide-FISH results show that these 3 genes are all located on chromosome 7 of $R$. wichurana. Gathering all results from physical mapping on mitotic [29] and pachytene chromosomes and genetic mapping [48], it can be hypothesized that FvChr6 has a complex evolutionary history since Fragaria and Rosa were diverged from a common ancestor.

\section{Conclusion}

Tyramide-FISH mapping of single-copy genes on pachytene chromosomes opens possibilities for the development of detailed physical maps of $R$. wichurana chromosomes. This approach will assist the integration of physical and genetic maps and will accelerate comparative genomic studies of genera in the Rosaceae family. For further experiments, cytogenetic marker development would be valuable for the identification of all pachytene chromosomes of $R$. wichurana. The application of larger numbers of single-copy gene probes covering all chromosomes of the karyotype of Rosa and the construction of the integrated genetic and physical maps for all chromosomes of $R$. wichurana is the scope of our future research.

\section{Availability of supporting data}

The partial sequences of the gene fragments used for Tyramide-FISH are available as Additional file 1.

\section{Additional file}

Additional file 1: The partial sequences of the clones used for Tyramide-FISH.

\section{Competing interests}

The authors declare that they have no competing interests

\section{Authors' contributions}

IK: designed and performed the experiments and wrote the paper; KVL and LK conceived of the study, and participated in its design and coordination and wrote the paper. All authors read and approved the final manuscript.

\section{Acknowledgements}

We thank Jorien Oomen for her technical assistance.

\section{Author details}

'Department of Genetics, Biotechnology, Plant Breeding and Seed Science, Russian State Agrarian University - Moscow Timiryazev Agricultural Academy, Timiryazevskay str.49, 127550 Moscow, Russia. ${ }^{2}$ Center of Molecular Biotechnology, Russian State Agrarian University - Moscow Timiryazev Agricultural Academy, Listvennichnaya Alleya 5, 127550 Moscow, Russia. ${ }^{3}$ Plant Sciences Unit, Applied Genetics and Breeding, Institute for Agricultural and Fisheries Research (ILVO), Caritasstraat 21, 9090 Melle, Belgium.

Received: 11 February 2015 Accepted: 16 June 2015

Published online: 02 July 2015

\section{References}

1. Robertson KR, Phipps JB, Rohrer JR, Smith PG. A synopsis of genera in Maloideae (Rosaceae). Systematic Botany. 1991;16(2):376-394.

2. Dirlewanger E, Graziano E, Joobeur T, Garriga-Calderé F, Cosson P, Howad W, et al. Comparative mapping and marker-assisted selection in Rosaceae fruit crops. Proc Natl Acad Sci U S A. 2004;101(26):9891-6.

3. Potter D, Eriksson T, Evans RC, Oh S, Smedmark J, Morgan DR, et al. Phylogeny and classification of Rosaceae. Plant Syst Evol. 2007;266(1-2):5-43.

4. Shulaev V, Sargent DJ, Crowhurst RN, Mockler TC, Folkerts O, Delcher AL, et al. The genome of woodland strawberry (Fragaria vesca). Nat Genet. 2011:43(2):109-16.

5. Longhi S, Giongo L, Buti M, Surbanovski N, Viola R, Velasco R, Ward JA, Sargent DJ. Molecular genetics and genomics of the Rosoideae: state of the art and future perspectives. Horticulture Research. 2014;1:1.

6. Cairns T. Modern Roses XI. San Diego: Academic; 2000.

7. Koopman WJ, Wissemann V, De Cock K, Van Huylenbroeck J, De Riek J, Sabatino GJ, et al. AFLP markers as a tool to reconstruct complex relationships: a case study in Rosa (Rosaceae). Am J Bot. 2008;95(3):353-66.

8. Gudin S. Rose breeding technologies. In: III International Symposium on Rose Research and Cultivation. 547. 2000. p. 23-33.

9. Wu J, Wang Z, Shi Z, Zhang S, Ming R, Zhu S, et al. The genome of the pear (Pyrus bretschneideri Rehd.). Genome Res. 2013;23(2):396-408.

10. Verde I, Abbott AG, Scalabrin S, Jung S, Shu S, Marroni F, et al. The highquality draft genome of peach (Prunus persica) identifies unique patterns of genetic diversity, domestication and genome evolution. Nat Genet. 2013;45(5):487-94.

11. Velasco R, Zharkikh A, Affourtit J, Dhingra A, Cestaro A, Kalyanaraman A, et al. The genome of the domesticated apple (Malus [times] domestica Borkh.). Nat Genet. 2010;42(10):833-9.

12. Gale M, Devos K. Plant comparative genetics after 10 years. Science. 1998;282(5389):656-9.

13. Paterson AH, Bowers JE, Burow MD, Draye X, Elsik CG, Jiang C-X, et al. Comparative genomics of plant chromosomes. Plant Cell Online. 2000;12(9):1523-39.

14. Cheng Z, Presting GG, Buell CR, Wing RA, Jiang J. High-resolution pachytene chromosome mapping of bacterial artificial chromosomes anchored by genetic markers reveals the centromere location and the distribution of genetic recombination along chromosome 10 of rice. Genetics. 2001;157(4):1749-57.

15. Giraut L, Falque M, Drouaud J, Pereira L, Martin OC, Mézard C. Genome-wide crossover distribution in Arabidopsis thaliana meiosis reveals sex-specific patterns along chromosomes. PLoS Genet. 2011;7(11):e1002354.

16. Poursarebani N, Nussbaumer T, Šimková H, Šafář J, Witsenboer H, Oeveren J, et al. Whole genome profiling (WGP'M) and shotgun sequencing delivers an anchored, gene-decorated, physical map assembly of bread wheat chromosome 6A. Plant J. 2014;79:334-47.

17. Talbert PB, Henikoff S. Centromeres convert but don't cross. PLoS Biol. 2010;8(3):e1000326.

18. Karafiátová M, Bartoš J, Kopecký D, Ma L, Sato K, Houben A, et al. Mapping nonrecombining regions in barley using multicolor FISH. Chromosome Res. 2013;21(8):739-51.

19. Staub JE, Serquen FC, Gupta M. Genetic markers, map construction, and their application in plant breeding. HortSci. 1996;31(5):729-41.

20. Jiang J, Gill BS. Current status and the future of fluorescence in situ hybridization (FISH) in plant genome research. Genome. 2006;49(9):1057-68.

21. Shearer LA, Anderson LK, de Jong H, Smit S, Goicoechea JL, Roe BA, Hua A, Giovannoni JJ, Stack SM. Fluorescence In Situ Hybridization and Optical 
Mapping To Correct Scaffold Arrangement in the Tomato Genome. G3: Genes| Genomes| Genetics. 2014;doi: 10.1534/g3.114.011197.

22. Huang S, Li R, Zhang Z, Li L, Gu X, Fan W, et al. The genome of the cucumber, Cucumis sativus L. Nat Genet. 2009;41(12):1275-81.

23. Chamala S, Chanderbali AS, Der JP, Lan T, Walts B, Albert VA, et al. Assembly and validation of the genome of the nonmodel basal angiosperm Amborella. Science. 2013;342(6165):1516-7.

24. Ma Y, Islam-Faridi M, Crane C, Ji Y, Stelly D, Price H, et al. In situ hybridization of ribosomal DNA to rose chromosomes. J Hered. 1997:88(2):158-61.

25. Fernández-Romero M, Torres A, Millán T, Cubero J, Cabrera A. Physical mapping of ribosomal DNA on several species of the subgenus Rosa. Theor Appl Genet. 2001;103(6-7):835-8.

26. Akasaka M, Ueda Y, Koba T. Karyotype analyses of five wild rose species belonging to septet A by fluorescence in situ hybridization. Chromosome Sci. 2002;6(1):17-26.

27. Akasaka M, Ueda Y, Koba T. Karyotype analysis of wild rose species belonging to septets B, C and D by molecular cytogenetic method. Breed Sci. 2003;53(2):177-82

28. Tian M, Zhang T, Tang K-X, Zhang H, Wang Q-G LIS-B, Yan H-J, et al. FISH Analysis of $45 \mathrm{~S}$ rDNA on the Chromosomes of Chinese Old Garden Roses. J Yunnan Agric Univ (Natural Science). 2013;3:020.

29. Kirov I, Van Laere K, De Riek J, De Keyser E, Van Roy N, Khrustaleva L. Anchoring Linkage Groups of the Rosa Genetic Map to Physical Chromosomes with Tyramide-FISH and EST-SNP Markers. PLoS One. 2014;9(4):e95793.

30. Hans de Jong J, Fransz P, Zabel P. High resolution FISH in plants-techniques and applications. Trends Plant Sci. 1999;4(7):258-63.

31. Fransz PF, Armstrong $S$, de Jong JH, Parnell LD, van Drunen C, Dean C, et al. Integrated Cytogenetic Map of Chromosome Arm 4S of A. thaliana: Structural Organization of Heterochromatic Knob and Centromere Region. Cell. 2000;100(3):367-76.

32. Kulikova O, Gualtieri G, Geurts R, Kim DJ, Cook D, Huguet T, et al. Integration of the FISH pachytene and genetic maps of Medicago truncatula. Plant J. 2001;27(1):49-58.

33. Zhong X-B, Bodeau J, Fransz P, Williamson V, van Kammen A, De Jong J, et al. FISH to meiotic pachytene chromosomes of tomato locates the root-knot nematode resistance gene $\mathrm{Mi}-1$ and the acid phosphatase gene Aps-1 near the junction of euchromatin and pericentromeric heterochromatin of chromosome arms 6 S and 6 L, respectively. Theor Appl Genet. 1999;98(3-4):365-70.

34. Szinay D, Chang SB, Khrustaleva L, Peters S, Schijlen E, Bai Y, et al. Highresolution chromosome mapping of BACS using multi-colour FISH and pooled-BAC FISH as a backbone for sequencing tomato chromosome 6 . Plant J. 2008:56(4):627-37.

35. Cheng Z, Buell CR, Wing RA, Jiang J. Resolution of fluorescence in-situ hybridization mapping on rice mitotic prometaphase chromosomes, meiotic pachytene chromosomes and extended DNA fibers. Chromosome Res. 2002;10(5):379-87.

36. Ziolkowski PA, Kaczmarek M, Babula D, Sadowski J. Genome evolution in Arabidopsis/Brassica: conservation and divergence of ancient rearranged segments and their breakpoints. Plant J. 2006;47(1):63-74

37. Ziolkowski PA, Sadowski J. FISH-mapping of rDNAs and Arabidopsis BACs on pachytene complements of selected Brassicas. Genome. 2002;45(1):189-97.

38. Lysak MA, Pecinka A, Schubert I. Recent progress in chromosome painting of Arabidopsis and related species. Chromosome Res. 2003;11(3):195-204.

39. Fransz P, Armstrong S, Alonso-blanco C, Fischer TC, Torres-ruiz RA, Jones G. Cytogenetics for the model system Arabidopsis thaliana. Plant J. 1998;13(6):867-76.

40. lacia AAS, Pinto-Maglio CA. Mapping pachytene chromosomes of coffee using a modified protocol for fluorescence in situ hybridization. AoB Plants. 2013:5:plt040

41. De Capdeville G, Júnior MTS, Szinay D, Diniz LEC, Wijnker E, Swennen R, et al. The potential of high-resolution BAC-FISH in banana breeding. Euphytica. 2009;166(3):431-43.

42. Dugo MDLL, Satovic Z, Millan T, Cubero Jl, Rubiales D, Cabrera A, et al. Genetic mapping of QTLs controlling horticultural traits in diploid roses. Theor Appl Genet. 2005;111(3):511-20.

43. Moghaddam HH, Leus L, De Riek J, Van Huylenbroeck J, Van Bockstaele E. Construction of a genetic linkage map with SSR, AFLP and morphological markers to locate QTLs controlling pathotype-specific powdery mildew resistance in diploid roses. Euphytica. 2012;184:413-27.

44. Crespel L, Chirollet M, Durel CE, Zhang D, Meynet J, Gudin S. Mapping of qualitative and quantitative phenotypic traits in Rosa using AFLP markers. Theor Appl Genet. 2002;105:1207-14.

45. Spiller M, Linde M, Hibrand-Saint Oyant L, Tsai CJ, Byrne DH, Smulders MJ, et al. Towards a unified genetic map for diploid roses. Theor Appl Genet. 2011;122(3):489-500

46. Shupert DA, Byrne DH, Pemberton HB. Inheritance of flower traits, leaflet number and prickles in roses. Acta Horticult. 2007;751:331-5.

47. Kirov I, Divashuk M, Van Laere K, Soloviev A, Khrustaleva L. An easy "SteamDrop" method for high quality plant chromosome preparation. Mol Cytogenet. 2014;7(1):21.

48. Gar O, Sargent DJ, Tsai C-J, Pleban T, Shalev G, Byrne DH, et al. An autotetraploid linkage map of rose (Rosa hybrida) validated using the strawberry (Fragaria vesca) genome sequence. PLoS One. 2011;6(5):e20463.

49. Henegariu O, Bray-Ward P, Ward DC. Custom fluorescent-nucleotide synthesis as an alternative method for nucleic acid labeling. Nat Biotechnol. 2000;18(3):345-8.

50. Gerlach W, Bedbrook J. Cloning and characterization of ribosomal RNA genes from wheat and barley. Nucleic Acids Res. 1979;7(7):1869-85.

51. Reeves A. MicroMeasure: a new computer program for the collection and analysis of cytogenetic data. Genome. 2001;44(3):439-43.

52. Yokoya K, Roberts A, Mottley J, Lewis R, Brandham P. Nuclear DNA amounts in roses. Ann Bot. 2000;85(4):557-61.

53. Martin R, Busch W, Herrmann R, Wanner G. Efficient preparation of plant chromosomes for high-resolution scanning electron microscopy. Chromosome Res. 1994;2(5):411-5.

54. Dick $C$, Johns $E$. The effect of two acetic acid containing fixatives on the histone content of calf thymus deoxyribonucleoprotein and calf thymus tissue. Exp Cell Res. 1968;51(2):626-32.

55. Sugiyama S, Yoshino T, Kanahara H, Shichiri M, Fukushi D, Ohtani T. Effects of acetic acid treatment on plant chromosome structures analyzed by atomic force microscopy. Anal Biochem. 2004;324(1):39-44.

56. Bobrow MN, Shaughnessy KJ, Litt GJ. Catalyzed reporter deposition, a novel method of signal amplification: II. Application to membrane immunoassays. J Immunol Methods. 1991;137(1):103-12.

57. Zhong X-B, de Jong JH, Zabel P. Preparation of tomato meiotic pachytene and mitotic metaphase chromosomes suitable for fluorescencein situ hybridization (FISH). Chromosome Res. 1996;4(1):24-8,

58. Cheng Z, Buell CR, Wing RA, Gu M, Jiang J. Toward a cytological characterization of the rice genome. Genome Res. 2001;11(12):2133-41.

59. Wang C-JR, Harper L, Cande WZ. High-resolution single-copy gene fluorescence in situ hybridization and its use in the construction of a cytogenetic map of maize chromosome 9. Plant Cell Online. 2006;18(3):529-44.

60. Pérez R, De Bustos A, Jouve N, Cuadrado A. Localization of Rad50, a single-copy gene, on group 5 chromosomes of wheat, using a FISH protocol employing tyramide for signal amplification (Tyr-FISH). Cytogenet Genome Res. 2009;125(4):321-8

61. Hanson RE, Zwick MS, Choi S, Islam-Faridi MN, Wing RA, Price H, et al. Fluorescent in situ hybridization of a bacterial artificial chromosome. Genome. 1995;38(4):646-51.

62. Khrustaleva L, Kirov I, Romanov D, Budylin M, Lapitskaya I, Kiseleva A, et al. The chromosome organization of genes and some types of extragenic DNA in Allium. Acta Horticult. 2012:969:43-51.

\section{Submit your next manuscript to BioMed Central and take full advantage of:}

- Convenient online submission

- Thorough peer review

- No space constraints or color figure charges

- Immediate publication on acceptance

- Inclusion in PubMed, CAS, Scopus and Google Scholar

- Research which is freely available for redistribution 